\title{
A Newly Designed Titanium Anode for Oxygen Evolution at High Current Densities
}

\author{
Yoichi KAMEGAYA*, Kouki SASAKI, Masayuki OGURI, \\ Tomoyoshi ASAKI and Takashi MITAMURA ${ }^{\dagger}$
}

Received February 10, 1993 ; Accepted March 29, 1993

\section{INTRODUCTION}

Although lead alloys are used as an insoluble anode in the electroplating industry, they are attacked to some extent even at low current densities; the surface oxide is easily detached from the substrate into the electrolytic solution, and the deposited metal on the cathode is contaminated by these impurities. Therefore, continuous filtration is an unavoidable procedure in the process of electroplating. Labor costs for the renewal of the heavy metal anode are also an expensive problem. However, these difficulties could be eliminated if a non-consumable coated anode which has a high performance could be used $1 \sim 3$ ).

This paper deals with a newly designed titanium anode for the electrolysis of sulfate solution at high current densities.

\section{ELECTRODE STRUCTURE}

The anode material presented here consists of a multilayered oxide coating on the titanium substrate and a member of the Metal Oxide Dispersed Anodes or MODE ${ }^{\circledR 4}$ ). A mixture of iridium oxide and the oxide of other metals, either noble or non-noble metals, was selected as the active mass, or electrocatalyst, for oxygen

R \& D Department, Ishifuku Metal Industry Company, Ltd. (12-30 Aoyagi 2-chome, Soka-shi 340 Japan)

$\dagger$ Department of Applied Chemistry, Faculty of Engineering, Saitama University (255 Shìmo-ohkubo, Urawa-shi 338 Japan)

Key Words: Coated Anode, Titanium, Oxygen Evolution, Iridium Oxide evolution from the sulfate solution. The titanium substrate is coated with the interlayers to prevent physical and chemical attack as illustrated in Fig. 1. That is, a thin titanium oxide layer next to the substrate is electroconductive and prevents the substrate from corrosion. The second layer consists of a mixture of platinum and the oxide of valve metals, which resists corrosion. This second layer also contributes the bonding of the active mass with the substrate (MODE ${ }^{\top}-\mathrm{H}$ ).

MODE $^{\oplus}-\mathrm{J}$ has an additional layer of valve metal oxide between the platinum dispersed layer and the electrocatalyst to prevent corrosion troubles under high current densities.

\section{EXPERIMENTAL}

The polarization was measured by the conventional galvanostatic method. The electrode potential was referred to the standard hydrogen electrode (SHE). The IR drop of solution between

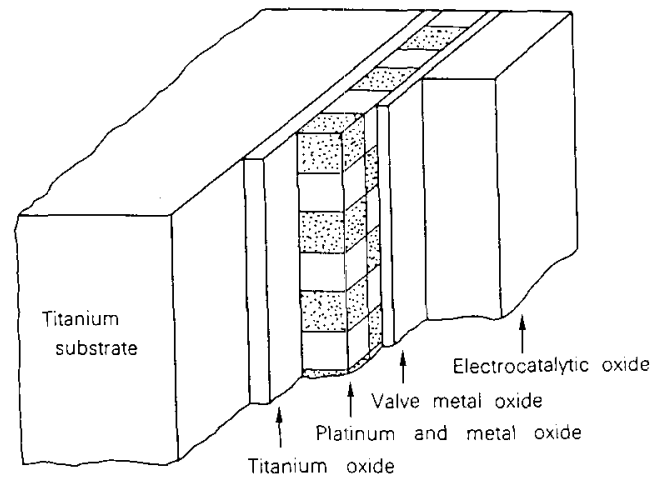

Fig. 1 Structure of MODE - J. 
the working electrode and a Luggin-Haber probe was corrected by the current-interruption method. A mixed solution of $1 \mathrm{M} \mathrm{H}_{2} \mathrm{SO}_{4}$ and $1 \mathrm{M}$ $\mathrm{Na}_{2} \mathrm{SO}_{4}$ was employed as the electrolytic solution of this experiment.

For the life test, it was conducted in the laboratory with a zinc electroplating solution taken from a plant. The solution was agitated continuously and renewed every ten days. A platinum cathode having an area of fifty times the area of the test anode was employed to keep the cathode's polarization low and to prevent the deposition of zinc. The electric resistance across the coated layer was measured by using a gold wire of $1 \mathrm{~mm}$ in diameter as the contact under a given weight $(57 \mathrm{~g})$ since the resistance is an important factor of the multilayer coated electrode.

The electrode surface was examined by the fluorescence $X$ - ray spectroscopy to evaluate the loss of active material caused by electrolysis.

\section{RESULTS AND DISCUSSION}

MODE $^{-}-\mathrm{H}$ has been used as a non-consumable anode for electroplating of copper and tin at a current density lower than $50 \mathrm{~A} / \mathrm{dm}^{2}$ in acidified sulfate solution, and the service life is more than one year under normal conditions in practical plant. Thus, the MODE ${ }^{\infty}-\mathrm{H}$ material was selected and tested as the candidate for the durable anode for the electro - galvanizing process or line (EGL). From the view point of economy, an anode life of at least half a year is necessary for plant. Thus, MODE ${ }^{\oplus}-\mathrm{H}$ was tested in a laboratory cell

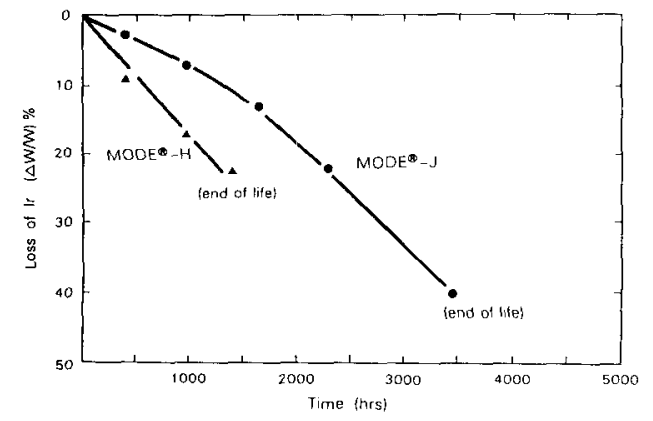

Fig. 2 Consumption of the active mass of MODE in zinc electroplating solution at $60^{\circ} \mathrm{C}$ and $135 \mathrm{~A} / \mathrm{dm}^{2}$. containing zinc electroplating solution taken from a plant at $135 \mathrm{~A} / \mathrm{dm}^{2}$. The cell voltage increased noticeably when the percent loss of the active mass was decreased by about $25 \%$, and hence its point was considered to show the electrode life (Fig. 2).

The polarization behavior was measured. The potential of a degraded anode is about $0.2 \mathrm{~V}$ high compared to that of a fresh anode over the range of current density examined as shown in Fig. 3. The Tafel slope was also increased from 80 $\mathrm{mV}$ to $100 \mathrm{mV} /$ decade, probably caused by the increase in electric resistance through the coated layer. The results suggest that the improvement of the corrosion resistance is of the great importance for practical application of the anode operated at high current densities.

With above concept, a relatively thin layer composed of valve metal oxide was loaded between the platinum dispersed layer and the surface catalyst to prevent the penetration of electrolytic solution through the metal oxide layer containing platinum particles as shown in Fig. 1.

The chemical composition and the structure of the laminated interlayer were designed to lower an overall voltage drop. The active mass was also modified to aim at ensuring low oxygen overvoltage at high current density. Thus a modified $\mathrm{MODE}^{\circledR}, \mathrm{MODE}^{\circledR}-\mathrm{J}$, has been developed. The electric resistance through the coated layer of this anode is about $0.2 \mathrm{ohm}$, one quater of conventional MODE $^{\circledR}-\mathrm{H}$. The polarization curve of $\mathrm{MODE}^{\circledR}-\mathrm{J}$ is almost the same to that of

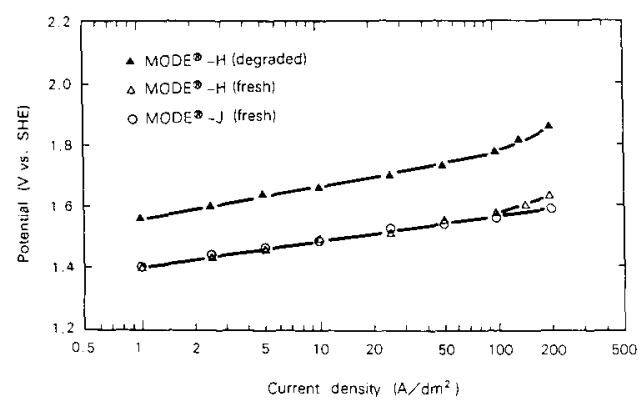

Fig. 3 Polarization curves of $\mathrm{MODE}^{*}$ in a mixed solution of $1 \mathrm{M} \mathrm{H}_{2} \mathrm{SO}_{4}$ and $1 \mathrm{M} \mathrm{Na}_{2} \mathrm{SO}_{4}$ at $60^{\circ} \mathrm{C}$. 
MODE $^{\circledR}-\mathrm{H}$ as shown in Fig. 3. The Tafel line is straight in a wide range of current density while the potential of $\mathrm{MODE}^{\circledR}-\mathrm{H}$ deviated slightly from the straight line at high current densities. $\mathrm{MODE}^{\circledR}-\mathrm{J}$ was also tested with zinc electroplating solution taken from a plant. The current density was kept constant at $135 \mathrm{~A} / \mathrm{dm}^{2}$. The service life was more than twice of $\mathrm{MODE}^{\circledR}-\mathrm{H}$. This anode worked actively until the active mass was lost by about $40 \%$ while the utilization of the coated layer on $\mathrm{MODE}^{\circledR}-\mathrm{H}$ was only $25 \%$.

The pilot scale zinc plating electrolyzers equipped with MODE $^{\circledR}-J$ were operated in several locations for more than 6 months. One of them has already converted all the alloy anodes into $\mathrm{MODE}^{\circledR}-\mathrm{J}$, and is working well under optimized conditions with no trouble.

\section{REFERENCES}

1) F. Hine, Soda and Chlorine, 40, 246 (1989).

2) M. Takahashi, Soda and Chlorine, 40, 449 (1989).

3) Japan Patent, Kokai Hei-2-232387 (1990).

4) T. Asaki, Y. Kamegaya and K. Takayasu, $J$. Electrochem. Soc., 132, 1895 (1985). 